\title{
ECONOMY OF DESIGN OF FLEXIBLE AND RIGID PAVEMENTS
}

\author{
Divyansh Mittal, Shalu Meena, Deepak Phagna, Rabindra Kumar \\ UG Students \\ Civil Engineering Department \\ N.I.T. Kurukshetra, Haryana, India
}

\author{
S.N. Sachdeva \\ Professor \\ Civil Engineering Department \\ N.I.T. Kurukshetra, Haryana, India
}

\begin{abstract}
It is generally believed that rigid pavements consisting of cement concrete have more cost of construction than flexible or bituminous pavements. This paper brings forth the economy of design of flexible and rigid pavements. The designs for flexible and rigid pavement for a given road have been worked out for various values of effective California Bearing Ratio (CBR) of subgrade soil varying from $3 \%$ to $8 \%$ and initial traffic on the road varying from 500 to 6000 commercial vehicles per day. The designs have been evolved using latest relevant guidelines of Indian Roads Congress (IRC). IRC:37-2012 and 2018 have been used for the design of flexible pavements and IRC:58-2015 has been used for the design of rigid pavements. The design of flexible pavement is based upon fatigue and rutting failure of the pavement. For rigid pavement the design is based upon fatigue analysis of bottom up cracking and top down cracking of the pavement. The rate analysis for various items of work as per designs obtained and the cost estimation for the designed pavements have been done as per IRC guidelines. The paper discusses the designs of both flexible and rigid pavements, the effect of CBR of subgrade and traffic on the designed thickness and the economy of construction of these pavements. It is found from the results that the construction of rigid pavements may not always be more costly. The paper in fact shows that they are more economical to construct for conditions of low subgrade strength and high volume of traffic on the road.
\end{abstract}

Keywords - Design, Flexible pavement, Rigid pavement, Thickness of pavement, Cost of pavement

\section{INTRODUCTION}

Transportation is vital for the overall development of any country. Transportation by road system is the only mode which could give maximum flexibility of service from origin to destination to one and all. It is most suited for carrying goods and people to and from rural areas which are not served by other modes of transport.

The road network in India is over 58 lakh $\mathrm{km}$ which is second largest network in the world. The United States with 66.45 lakh kilometers [1] has more roads. The road density in India is more than $1.70 \mathrm{~km}$ of roads per square $\mathrm{km}$ of area. This is higher than Japan $(0.91 \mathrm{~km})$ and the United States $(0.68 \mathrm{~km})$. The road density of India is also higher than China $(0.47 \mathrm{~km})$ and Russia $(0.08 \mathrm{~km})$ [2].

Research Schemes R-6 (1995) [3] and R-56 (1999) [4] of Ministry of Road Transport and Highways, the work done by Reddy et al. (2001) [5], These et al. (1996) [6], Kumar et al. (2008) [7] and the experience provided by MEPDG (2008) guidelines [8] paved the way for the development of semi mechanistic design guidelines for flexible pavements in India as IRC:37-2012 [9] and IRC:37-2018 [10]. IRC:37 guidelines are based upon fatigue and rutting failure criteria of pavement. It provides the mathematical models for calculating the allowable horizontal tensile strain beneath the bituminous layer for fatigue failure and allowable vertical compressive strain over the subgrade for rutting failure of the pavement. IITPAVE software provided with IRC:37 is used to find the actual strains at these critical locations. In order that the assumed design is safe, the actual strain should be less than the allowable strain.

IRC:58 (2015) [11] guidelines are based upon fatigue analysis of bottom up cracking and top down cracking of rigid pavement. The cumulative fatigue damage (CFD) for both bottom up cracking (BUC) and top down cracking (TDC) is found out. If it is less than one, the assumed thickness of the pavement is safe. The CFD analysis is made for various classes of loads for their expected number of repetitions during the design life of the pavement.

The designs of both flexible and rigid pavements have been worked out for a 4-lane road with dual carriageway, each 7.0 $\mathrm{m}$ wide, located near Kurukshetra, Haryana, India for various values of effective CBR of subgrade varying from $3 \%$ to $8 \%$ and initial traffic varying from 500 commercial vehicles per day (CVPD) to 6000 CVPD on the road. The design life for flexible pavement is considered as 20 years whereas for rigid pavement it is taken as 30 years. The annual growth rate of commercial vehicles is taken as $6.0 \%$. The shoulders for both the flexible and rigid pavements are assumed as earthen shoulders. 
The following sections discuss the designs of both type of pavements, the effect of CBR of subgrade and traffic on the designed thickness and the economy of construction of these pavements.

\section{DeSIGN OF FleXIBle PAVEMENT}

In the design of flexible pavement, fatigue and rutting criteria have been considered for $90 \%$ reliability. The allowable strains have been worked out with the help of equations provided in IRC 37 [9] [10] and the actual strains are obtained from IITPAVE.

IITPAVE is a software provided with IRC:37 which provides us with the actual values of stresses and strains for different load cases.

As per IRC:37, the design traffic is calculated using the equation 1 .

$\mathrm{N}=365 * \mathrm{~A} * \mathrm{D} * \mathrm{~F}\left[(1+\mathrm{r})^{\mathrm{n}}-1\right] / \mathrm{r}$

Where,

$\mathrm{N}=$ Cumulative number of standard axles

$r=$ annual growth rate of commercial vehicles $(\mathrm{CVs})$ in perecent

$\mathrm{A}=$ Initial traffic in the year of completion of construction in number of commercial vehicles per day (CVPD)

$\mathrm{D}=$ Lane distribution factor. The lane distribution factor is required to specify the distribution of commercial traffic in each lane and direction to determine the total equivalent standard axle load to be considered for design.

$\mathrm{F}=$ Vehicle damage factor $(\mathrm{VDF})$

$\mathrm{n}=$ design life in years (20 years)

Allowable horizontal tensile strain beneath bituminous layer $\left(\varepsilon_{\mathrm{t}}\right)$ is calculated using equation 2 .

$\mathrm{N}_{\mathrm{f}}=0.5161 * \mathrm{C}^{*} 10^{-4}\left[1 / \mathcal{E}_{\mathrm{t}}\right]^{3.89} *\left[1 / \mathrm{M}_{\mathrm{Rm}}\right]^{0.854}$

where,

$\mathrm{N}_{\mathrm{f}}=$ Fatigue life of bituminous layer in cumulative number of standard axles

$\mathrm{C}=10^{\mathrm{M}}$

$\mathrm{M}=4.84[\{\mathrm{Vbe} /(\mathrm{Va}+\mathrm{Vbe})\}-0.69]$

$\mathrm{Va}=$ percent volume of air voids in the mix

Vbe $=$ percent volume of effective bitumen in the mix

$\mathrm{MRm}=$ Resilient Modulus of bituminous mix, $\mathrm{MPa}$

Allowable Vertical strain on subgrade, $\left(\mathcal{E}_{\mathrm{v}}\right)$ (for $90 \%$ reliability level) is found out using equation 3 .

$\mathrm{N}=1.41 * 10^{-8} *\left[1 / \mathcal{E}_{\mathrm{v}}\right]^{4.5337}$ where,

$\mathrm{N}_{\mathrm{R}}=$ Rutting life of subgrade in cumulative number of standard axles

Using design catalogues of IRC:37, values of thickness of various layers of pavement such as sub base, base, binder course and wearing course are assumed. For these assumed values of design thicknesses, IIT PAVE is used to find out actual tensile strain beneath bituminous layer caused by fatigue due to traffic and the vertical strain above the subgrade caused by rutting. If theses actual strains are less than the allowable strains calculated by equations 2 and 3, the assumed thicknesses of various layers are found to be safe and adopted as design thicknesses for the pavement. On this basis, the given flexible pavement has been designed for varying values of CBR of subgrade from $3 \%$ to $8 \%$ and initial traffic values from 500 to $6000 \mathrm{CVPD}$. The design results have been shown in table 1 .

Table 1 Design Thickness Values of Flexible Pavement

\begin{tabular}{|c|c|c|c|c|c|c|}
\hline \multirow{3}{*}{$\begin{array}{c}\text { CBR } \\
\text { of } \\
\text { Sub } \\
\text { Grade } \\
(\%)\end{array}$} & \multirow{2}{*}{$\begin{array}{l}\text { Initial } \\
\text { Traffic }\end{array}$} & \multicolumn{4}{|c|}{ Thickness of Layers (mm) } & \multirow{3}{*}{$\begin{array}{l}\text { Total } \\
\text { Thick } \\
\text {-ness }\end{array}$} \\
\hline & & $\begin{array}{l}\text { Wear } \\
\text {-ing }\end{array}$ & Binder & Base & $\begin{array}{l}\text { Sub } \\
\text { base }\end{array}$ & \\
\hline & (CVPD) & $*(\mathrm{BC})$ & $(\mathrm{DBM})$ & (WMM) & (GSB) & \\
\hline \multirow{4}{*}{3} & 500 & 40 & 80 & 250 & 370 & 740 \\
\hline & 2000 & 40 & 140 & 250 & 380 & 810 \\
\hline & 4000 & 50 & 150 & 250 & 380 & 830 \\
\hline & 6000 & 50 & 165 & 250 & 380 & 845 \\
\hline \multirow{4}{*}{4} & 500 & 40 & 70 & 250 & 320 & 680 \\
\hline & 2000 & 40 & 130 & 250 & 330 & 750 \\
\hline & 4000 & 50 & 135 & 250 & 330 & 765 \\
\hline & 6000 & 50 & 150 & 250 & 330 & 780 \\
\hline \multirow{4}{*}{6} & 500 & 40 & 55 & 250 & 250 & 595 \\
\hline & 2000 & 40 & 105 & 250 & 260 & 655 \\
\hline & 4000 & 50 & 120 & 250 & 260 & 680 \\
\hline & 6000 & 50 & 135 & 250 & 260 & 695 \\
\hline \multirow{4}{*}{8} & 500 & 40 & 55 & 250 & 190 & 535 \\
\hline & 2000 & 40 & 100 & 250 & 200 & 590 \\
\hline & 4000 & 50 & 110 & 250 & 200 & 610 \\
\hline & 6000 & 50 & 130 & 250 & 200 & 630 \\
\hline
\end{tabular}

*BC: Bituminous concrete, DBM: Dense bituminous macadam, WMM: Wet mix macadam, GSB : Granular subbase

It is observed from Table 1 that wearing course thickness increases with increase in traffic. However, for a given value of traffic, it remains unaffected with change in value of CBR of subgrade. Thickness of binder course of the pavement increases with traffic for a given value of CBR of subgrade and Its value is found to decrease for higher values of CBR of subgrade. Thickness of the base course is found to be same for all values of $\mathrm{CBR}$ and traffic considered in the study. Thickness of subbase layer of pavement decreases with increase in value of the CBR of the subgrade and is found to be largely unaffected with change in the value of traffic. 


\section{International Journal of Engineering Applied Sciences and Technology, 2020 \\ Vol. 4, Issue 12, ISSN No. 2455-2143, Pages 341-346 \\ Published Online April 2020 in IJEAST (http://www.ijeast.com)}

\section{DESIGN OF RIGID PAVEMENT}

Rigid pavement design has been done for the dual carriageway pavement provided with dowel and tie bars and earthen shoulders. It has been designed for varying initial traffic and subgrade strength using IRC 58: 2015. Percentage of traffic in predominant direction is taken as $50 \%$. Average number of axle per $\mathrm{CV}$ is taken as 2.35 .

CFD Analysis for BUC and TDC is done as per the guidelines given in IRC-58. Equations 4 to 9 are used to calculate maximum tensile stress at bottom of the slab and equation 10 is used to calculate maximum tensile stress at top of the slab.

(1) Maximum tensile stress at bottom of the slab (for Bottom-up cracking case)

(a) Single axle - Pavement with earthen shoulders

a) $\mathrm{k} \leq 80 \mathrm{Mpa} / \mathrm{m}$

$$
\mathrm{S}=-0.149-2.60\left(\mathrm{Yh}^{2} / \mathrm{kl}^{2}\right)+3.13 \mathrm{Ph} /\left(\mathrm{kl}^{4}\right)+0.0297 \Delta \mathrm{T}
$$

b) $\mathrm{k}>80 \mathrm{MPa} / \mathrm{m}, \mathrm{k} \leq 150 \mathrm{MPa} / \mathrm{m}$

$$
\mathrm{S}=-0.119-2.99\left(\mathrm{Yh}^{2} / \mathrm{kl}^{2}\right)+2.78 \mathrm{Ph} /\left(\mathrm{kl}^{4}\right)+0.0456 \Delta \mathrm{T}
$$

c) $\mathrm{k}>150 \mathrm{MPa} / \mathrm{m}$

$$
\mathrm{S}=-0.238+7.02\left(\mathrm{Yh}^{2} / \mathrm{kl}^{2}\right)+2.41 \mathrm{Ph} /\left(\mathrm{kl}^{4}\right)+0.0585 \Delta \mathrm{T}
$$

(b) Tandem axle - Pavement with earthen shoulders

a) $\mathrm{k} \leq 80 \mathrm{Mpa} / \mathrm{m}$

$$
\mathrm{S}=-0.223+2.73\left(\mathrm{Yh}^{2} / \mathrm{kl}^{2}\right)+1.335 \mathrm{Ph} /\left(\mathrm{kl}^{4}\right)+0.0229 \Delta \mathrm{T}
$$

b) $\mathrm{k}>80 \mathrm{MPa} / \mathrm{m}, \mathrm{k} \leq 150 \mathrm{MPa} / \mathrm{m}$

$$
\mathrm{S}=-0.276+5.78\left(\mathrm{Yh}^{2} / \mathrm{kl}^{2}\right)+1.14 \mathrm{Ph} /\left(\mathrm{kl}^{4}\right)+0.0404 \Delta \mathrm{T}
$$

c) $\mathrm{k}>150 \mathrm{MPa} / \mathrm{m}$

$$
\mathrm{S}=-0.3+9.88\left(\mathrm{Yh}^{2} / \mathrm{kl}^{2}\right)+0.965 \mathrm{Ph} /\left(\mathrm{kl}^{4}\right)+0.0543 \Delta \mathrm{T}
$$

(2) Maximum tensile stress at top of the slab (for Topdown cracking case)

$\mathrm{S}=-0.219+1.686 \mathrm{BPh} / \mathrm{kl}^{4}+168.48 \mathrm{~h}^{2} / \mathrm{kl}^{2}+0.1089 \Delta \mathrm{T}$

where,

$\mathrm{S}=$ flexural stress in slab, $\mathrm{MPa}$

$\Delta \mathrm{T}=$ maximum temperature differential in ${ }^{\circ} \mathrm{C}$ during day for bottom-up cracking

$=$ sum of the maximum night time negative temperature differential and built-in negative temperature differential in ${ }^{\circ} \mathrm{C}$ for top-down cracking

$\mathrm{h}=$ thickness of slab, $\mathrm{m}$

$\mathrm{k}=$ effective modulus of subgrade reaction, $\mathrm{MPa} / \mathrm{m}$

$1=$ radius of relative stiffness $=\left\{\mathrm{Eh}^{3} /\left(12 \mathrm{k}\left(1-\mu^{2}\right)\right)\right\}^{0.25}$

$\mathrm{E}=$ elastic modulus of concrete, $\mathrm{MPa}$ $\mu=$ Poisson's ratio of concrete

$\Upsilon=$ unit weight of concrete, $\mathrm{kN} / \mathrm{m}^{3}$

$\mathrm{P}=$ For bottom up cracking, single / tandem rear axle load $(\mathrm{kN})$

$=$ For top down cracking, $100 \%$ of rear single axle, $50 \%$ of rear tandem axle and $33 \%$ of rear tridem axle.

$\mathrm{B}=0.66$ for transverse joint with dowel bars (load transfer efficiency taken as $50 \%$ )

$=0.90$ for transverse joint without dowel bars (load transfer efficiency taken as $10 \%$ )

The fatigue analysis for various class of loads as per the commercial vehicles on the road is done for both bottom up cracking and top down cracking. The assumed thickness of the pavement is considered safe if the cumulative fatigue damage of both the analyses is less than 1 .

On the basis of the design, the results obtained for the thickness of Pavement Quality Concrete (PQC, M-40 grade) slab are shown in table 2. The PQC slab is provided over a layer of $100 \mathrm{~mm}$ thick Dry Lean Concrete (DLC) which in turn rests on a drainage layer of $150 \mathrm{~mm}$ Granular Subbase (GSB).

Table 2 Design Thickness Values of Rigid Pavement

It is observed from Table 2 that thickness of PQC slab increases with increase in traffic. However, the thickness first

\begin{tabular}{|c|c|c|c|c|}
\hline \multirow{2}{*}{$\begin{array}{c}\text { Initial } \\
\text { Traffi } \\
\text { c } \\
\text { (CVP } \\
\text { D) }\end{array}$} & \multicolumn{4}{|c|}{$\begin{array}{c}\text { Thickness of PQC Slab (mm) } \\
\text { for CBR of Subgrade as }\end{array}$} \\
\cline { 2 - 5 } & CBR 3\% & CBR 4\% & CBR 6\% & CBR 8\% \\
\hline 500 & 302 & 303 & 301 & 300 \\
\hline 2000 & 317 & 321 & 319 & 318 \\
\hline 4000 & 323 & 329 & 327 & 326 \\
\hline 6000 & 327 & 334 & 331 & 330 \\
\hline
\end{tabular}

increases and then decreases with increase in value of CBR of subgrade from $3 \%$ to $8 \%$.

\section{EFFECT OF CBR AND TRAFFIC ON DESIGN THICKNESS}

The effect of CBR on thickness of flexible pavement is shown in Fig. 1. 
International Journal of Engineering Applied Sciences and Technology, 2020

Vol. 4, Issue 12, ISSN No. 2455-2143, Pages 341-346

Published Online April 2020 in IJEAST (http://www.ijeast.com)

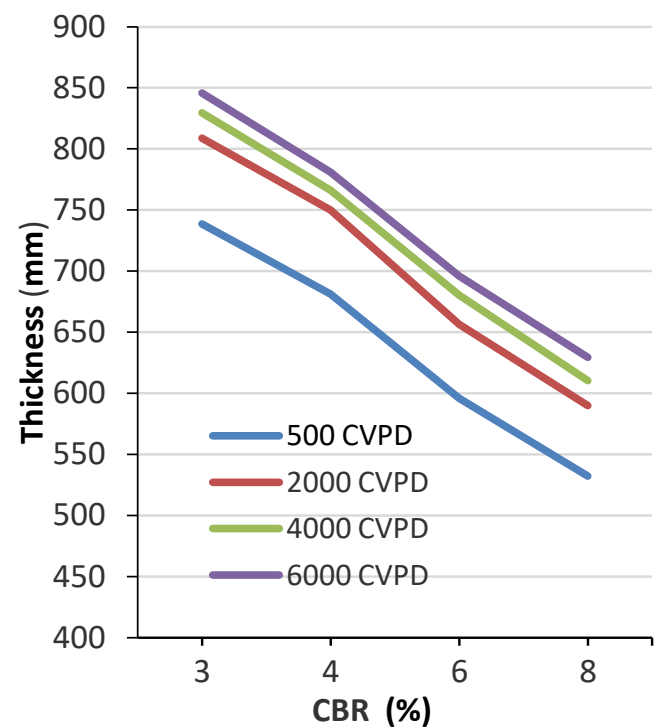

Fig. 1 Effect of CBR on Thickness of Flexible Pavement

It is seen from Fig. 1 that total thickness decreases with increase in value of CBR of subgrade for all values of traffic. The decrease in thickness with increase in CBR takes place almost in a uniform manner.

The effect of traffic on thickness of flexible pavement is shown in Fig. 2. It is seen from Fig. 2 that total thickness increases with increase in value of traffic for all values of CBR of subgrade. The increase in thickness with increase in traffic is more when the traffic increases from 500 to 2000 CVPD after which the increase in thickness from 2000 to 6000 CVPD is gradual.

The effect of CBR on thickness of rigid pavement is shown in Fig. 3.

It is seen from Fig. 3 that thickness of pavement first increases with increase in value of CBR of subgrade from $3 \%$ to $4 \%$ for all values of traffic. After that, from $4 \%$ to $8 \% \mathrm{CBR}$ value, the thickness of pavement decreases. However, the decrease in thickness with increase in CBR is quite insignificant.

The effect of traffic on thickness of rigid pavement is shown in Fig. 4.

It is observed from Fig. 4 that thickness of pavement increases with traffic for all values of CBR of subgrade. The rate of increase in thickness with increase in traffic is more when traffic increases from 500 to 2000 CVPD. After that from 2000 to 6000 CVPD, the rate of increase in thickness is gradual.

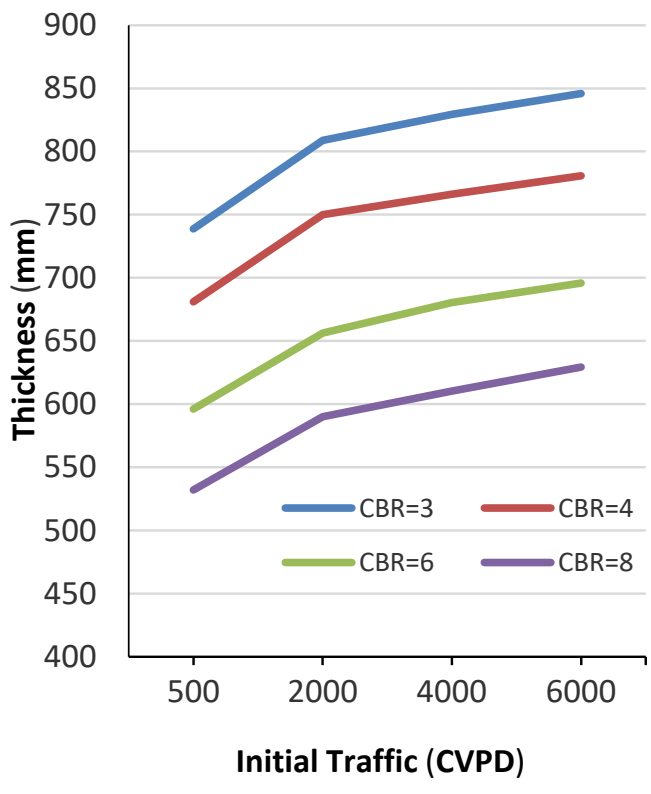

Fig. 2 Effect of Traffic on Thickness of Flexible Pavement

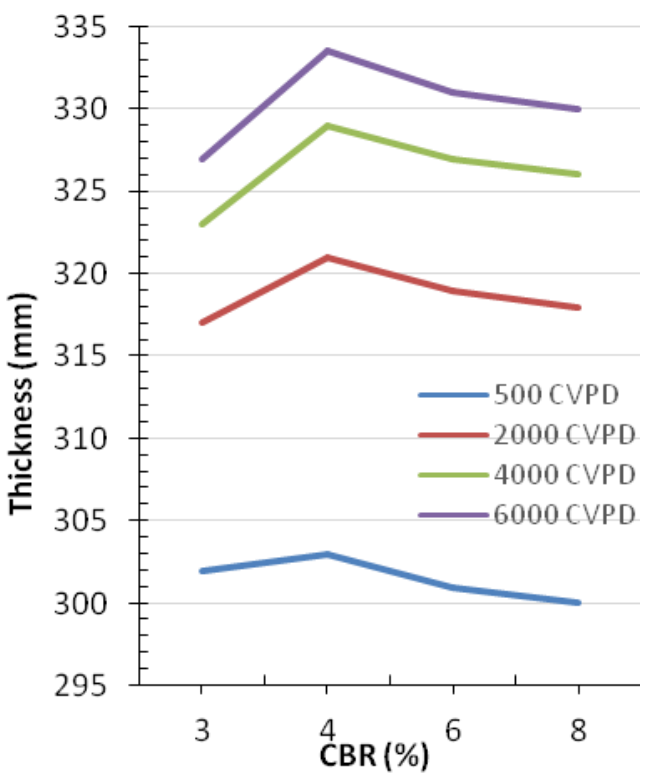

Fig. 3 Effect of CBR on Thickness of Rigid Pavement

\section{ECONOMY OF DESIGN}

MORTH Standard Data Book [12] has been used to do the rate analysis of various items of design. The rates obtained for a road located in Kurukshetra, Haryana, India for these items 


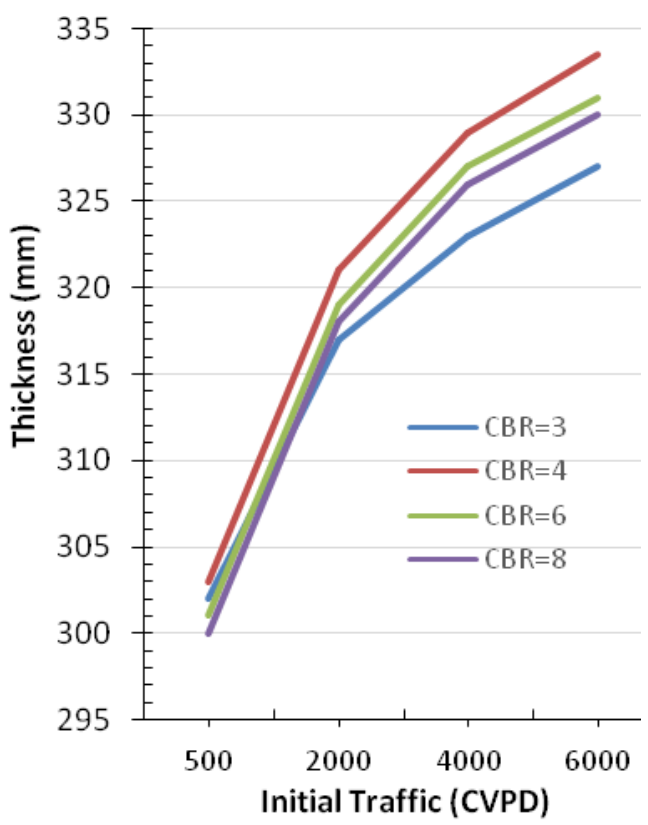

Fig. 4 Effect of Traffic on Thickness of Rigid Pavement

per cubic meter in Rupees are: $\mathrm{GSB}=1711, \mathrm{WMM}=6800$, $\mathrm{BC}=8100, \mathrm{DLC}=2723, \mathrm{PQC}=6529$, Prime $\mathrm{Coat}=22 / \mathrm{m} 2$, Tack coat: $9.3 / \mathrm{m} 2$. Using these rates the cost per square meter of rigid pavement (cement concrete pavement) and flexible pavement has been worked out. The ratio of cost of rigid to flexible pavement has been presented in Fig. 5. It is observed from Fig. 5 that when initial traffic on the road is 500 CVPD, the cost of construction of rigid pavement is 1.25 to 1.63 times more than the construction cost of flexible pavement for CBR varying from $3 \%$ to $8 \%$ respectively. However, for a high value of initial traffic as 6000 CVPD, the cost of construction of rigid pavement is 0.99 to 1.26 times the cost of flexible pavement with CBR of subgrade varying from $3 \%$ to $8 \%$. It is thus observed that a rigid pavement may not always be more costly than a flexible pavement as is generally believed. It is clear from Fig. 5 that for low values of CBR up to $3.0 \%$ and high values of initial traffic more than 5000 CVPD, the cost of construction of a rigid pavement may be less than the cost of construction of a flexible pavement. As is well known, the maintenance and vehicle operation cost is always less for rigid pavements than flexible pavements, the concrete pavements are going to be very cost effective especially for the conditions where CBR of subgrade soil is low and traffic on the road is very high.

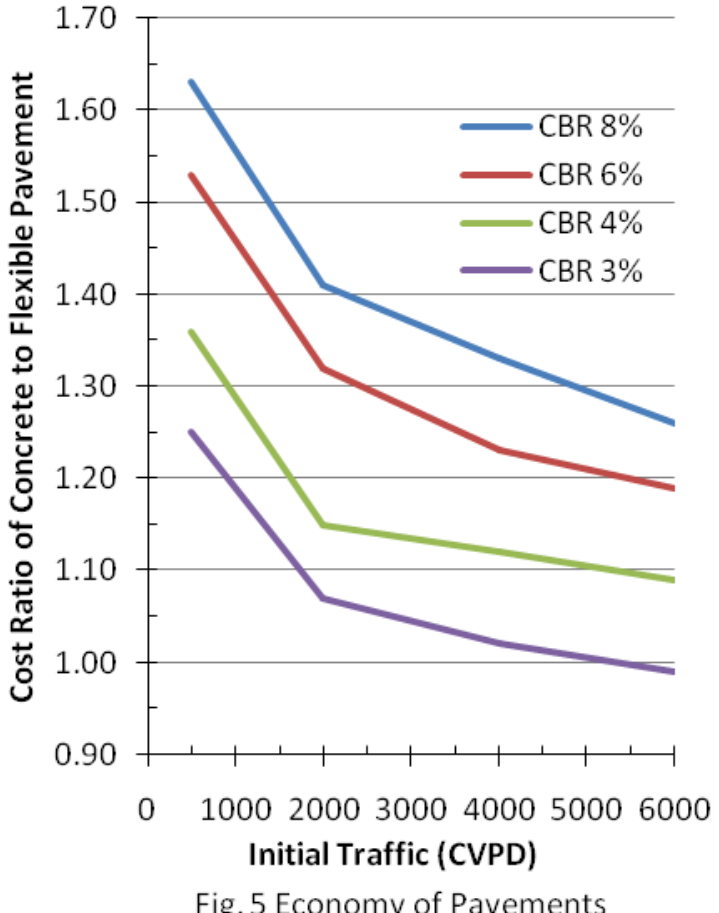

VI. CONCLUSION

The following main conclusions are drawn from the paper:

(i) Total thickness of flexible pavement decreases with increase in value of CBR of subgrade for all values of traffic. The decrease in thickness with increase in CBR takes place almost in a uniform manner.

(ii) Total thickness of flexible pavement increases with increase in value of traffic for all values of CBR of subgrade. The increase in thickness with increase in initial traffic is more when the traffic increases from 500 to 2000 CVPD after which the increase in thickness from 2000 to 6000 CVPD is gradual.

(iii) The thickness of rigid pavement first increases with increase in value of CBR of subgrade from $3 \%$ to $4 \%$ for all values of traffic. After that, from $4 \%$ to $8 \%$ CBR value, the thickness of pavement decreases. The decrease in thickness with increase in CBR is quite insignificant.

(iv) The thickness of rigid pavement increases with traffic for all values of CBR of subgrade. The rate of increase in thickness with increase in traffic is more when traffic increases from 500 to 2000 CVPD. After that from 2000 to $6000 \mathrm{CVPD}$, the rate of increase in thickness is gradual.

(v) For high value of initial traffic of 6000 CVPD, the cost of construction of rigid pavement is 0.99 to 1.26 times the cost of flexible pavement with $\mathrm{CBR}$ of subgrade varying from $3 \%$ to $8 \%$. 
(vi) The construction of rigid pavements is found to be more cost effective especially for the conditions where CBR of subgrade soil is low and traffic on the road is very high.

\section{REFERENCES}

[1] Basic Road Statistics of India for 2016-17 (2019), Ministry of Road Transport and Highways, GOI, New Delhi.

[2] Basic Road Statistics of India for 2015-16 (2018), Ministry of Road Transport and Highways, GOI, New Delhi.

[3] R-6 Research Scheme (1995), "Development of Methods such as Benkelman Beam Method for Estimation and Design of Overlays for Strengthening of Weak Pavements," Final Report submitted to the Ministry of Surface Transport (Roads Wing) by the Central Road Research Institute, New Delhi.

[4] R-56 Research Scheme (1999), "Analytical Design of Flexible Pavements," Final Report submitted to the Ministry of Surface Transport (Roads Wing) by the Civil Engineering Department, West Bengal.

[5] Reddy Amarnatha M., Reddy Sudhakar K. and Pandey B. B. (2001), "Design CBR of Subgrade for Flexible Pavements," Journal of Indian Roads Congress, pp. 61-69.

[6] These H. L., Beer M. de and Rust F. C. (1996), "Overview of the South African Mechanistic Pavement Design Analysis Method," Transportation Research Record, Washington DC.

[7] Kumar S. S., Sridhar R., Reddy Sudhakar K. and Bose S. (2008), "Analytical Investigation on the Influence of Loading and Temperature on Top-Down Cracking in Bituminous Layers," Journal of Indian Roads Congress, vol. 69, no. 1, pp. 71-77.

[8] MEPDG (2008), "Guide for Mechanistic-Empirical Pavement design Guide," AASHTO.

[9] IRC:37-2012, "Tentative Guidelines for the Design of Flexible Pavements," Indian Roads Congress, New Delhi.

[10] IRC:37-2018, "Guidelines for the Design of Flexible Pavements," Indian Roads Congress, New Delhi.

[11] IRC 58:2015, Guidelines for the design of plain jointed Rigid Pavements for highways, IRC, New Delhi.

[12] MORTH - Standard Data Book for Analysis of Rates, (2003), Indian Roads Congress, New Delhi. 